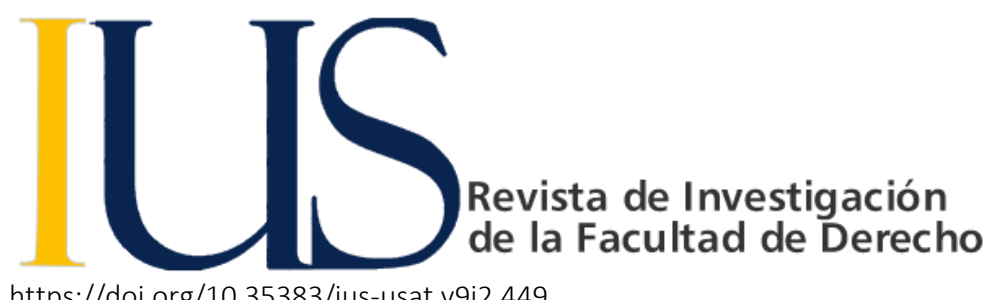

\title{
Propuesta de medidas jurídicas para la reinserción y permanencia laboral del adulto mayor en las políticas públicas peruanas
}

\section{Margarita del Pilar Díaz Llanos ${ }^{1}$}

\begin{tabular}{ll}
\hline INFORMACIÓN DEL ARTÍCULO & RESUMEN \\
\hline Historia del artículo: & El acelerado envejecimiento poblacional que atraviesa nuestro país repercute \\
Recibido el 31 de octubre de 2020 & en distintos ámbitos de la sociedad, entre ellos, el mercado laboral. El marco \\
Aceptado el 22 de diciembre de & jurídico y los planes nacionales sobre el adulto mayor, han previsto la \\
2020 & obligación estatal de promover y gestionar oportunidades de empleo \\
& productivo y formal para este sector de la población. Sobre esa base, en este \\
\hline $\begin{array}{l}\text { Palabras claves: } \\
\text { Adulto mayor } \\
\text { medidas jurídicas }\end{array}$ & estudio se proponen tres medidas jurídicas que deberán tenerse en cuenta \\
reinserción laboral & políticas públicas que al respecto se han adoptado en el Perú.
\end{tabular}

Proposal of legal measures for the reinsertion and labor permanence of the elderly adult in peruvian public policies

\section{ABSTRACT}

\section{Keywords: \\ Elderly \\ legal measures \\ labor reintegration \\ work permanence}

\begin{abstract}
The accelerated aging of the population that our country is going through has repercussions on different areas of society, including the labor market. The legal framework and national plans on the elderly have established the state obligation to promote and manage productive and formal employment opportunities for this sector of the population. On this basis, this study proposes three legal measures that should be taken into account to make the reintegration and employment of the elderly person effective in the public policies that have been adopted in Peru in this regard
\end{abstract}

\section{Introducción}

En América Latina y el Caribe, las personas con más de 60 años representaban el $11 \%$ del total de la población en el año 2019. Se estima que para el 2030 dicha población represente el $17 \%$ y, en el 2050 uno de cada cuatro habitantes en América Latina y el Caribe sea mayor de 60 años.

En Perú, el incremento de la proporción de adultos mayores es notable, pasa de constituir el 5,7\% de nuestra población en el año 1950, al 12,7\% en el año 2020.
El hecho de que un adulto mayor viva por muchos más años de los esperados plantea distintos escenarios, por ejemplo, su continuidad en la vida laboral y su subsistencia en condiciones óptimas que le garanticen una vida digna.

En nuestro país, el marco normativo a favor del adulto mayor ha establecido la obligación estatal de promover y gestionar oportunidades de empleo productivo y formal para este sector de la población.

\footnotetext{
${ }^{1}$ Investigadora Independiente, Abogada por la Universidad Católica Santo Toribio de Mogrovejo, Chiclayo, Perú. E-mail: pilar3496@hotmail.com ORCID: https://sandbox.orcid.org/0000-0001-5816-601X
} 
Sin embargo, no se han adoptado mecanismos específicos de promoción de empleo para este sector poblacional. En ese sentido se torna necesario formular la siguiente pregunta: ¿Qué medidas jurídicas deberán adoptarse para hacer efectivas las políticas públicas dirigidas a la reinserción y permanencia laboral de la población adulta mayor en el Perú?

El acceso al empleo del adulto mayor es un tópico que genera tesis a favor y en contra. Por un lado, se prioriza el derecho-deber a gozar del descanso tras una vida laboral, entendido como la jubilación. Mientras que, por otro, se reconoce el problema de desempleo en la tercera edad y se promueve la independencia y autonomía económica de los adultos mayores, a fin de garantizar un envejecimiento activo y saludable.

A través de la promoción de la reinserción y permanencia laboral de este grupo etario se podrá atender no solo el problema económico del adulto mayor, sino también otorgarle satisfacción personal. Después de todo, el trabajo dignifica al ser humano.

\section{El adulto mayor en el mercado laboral Perú}

\subsection{Hacia una definición del adulto mayor}

No se tiene una definición única de quién es un adulto mayor o de cuándo podemos considerarlo como tal, dado que existen tantas como autores que han pretendido definirlo. Sin embargo, es necesario tener en cuenta qué es en la vejez donde ubicamos a estas personas, por lo que es común llamarlos viejos o ancianos.

Desde el punto de vista cronológico, la vejez se inicia a los 60 años de edad, criterio establecido por las leyes de la mayoría de países del mundo (Huenchuan,2010). Se considera que ello responde al contenido sociocultural de esta etapa del desarrollo humano, dado que cada sociedad establece el umbral mínimo a partir del cual una persona se considera de edad avanzada.

Por otro lado, biológica o funcionalmente, corresponde referirnos a la vejez como aquel proceso de envejecimiento natural (Pérez, 2014). Desde esta perspectiva, generalmente, se asocia el término "viejo" a falta de capacidades o a la limitación de las mismas, cuando en realidad la vejez no representa necesariamente incapacidad. Entonces, la vejez puede definirse como una etapa o estadio de nuestras vidas.
Se debe hacer hincapié en que la vejez cronológica no tiene por qué coincidir con la vejez biológica. Así, personas de la misma edad cronológica -la que tienen según el calendario- no tienen necesariamente el mismo grado de dependencia e incluso algunas no padecen dependencia (Paz, 2010). Ello debido a que, en la vejez, como en cualquier fase del desarrollo humano, influyen distintos factores, no todos los adultos mayores se encuentran limitados funcionalmente.

Tradicionalmente, la concepción predominante de la vejez ha sido aquella que la concibe como una fase de escasez tanto económica como social. Es por ello que, si el Estado peruano aspira a un enfoque de reconocimiento de los derechos de las personas de la tercera edad, deberá partir por un cambio de paradigma, buscando el empoderamiento de este sector de la población a fin de lograr una sociedad constituida desde la perspectiva de la edad.

La mencionada postura implica considerar a los adultos mayores sujetos de derecho y no solo beneficiarios de éste. Es decir, verlos desde el enfoque de los derechos humanos y no desde el de sus necesidades (Palma, 2019). A las personas mayores les atañe disfrutar de ciertas facultades, pero también cumplir responsabilidades respecto de sí mismos, su familia y la sociedad. Estos argumentos conforman el debate en el que se erigen los temas de la vejez y el envejecimiento como un asunto público y de derechos humanos en la agenda mundial.

Es importante acotar que el proceso de la vejez no es algo anómalo o aislado en sí. En el mismo sentido, Kalish (citado en Pérez, 2014) señala que "un proceso natural e inevitable, que puede ser favorable o desfavorable" para el ser humano. Como hemos podido notar, la vejez es diversa, en tanto combina las experiencias y características de la persona y es también una construcción de la sociedad que se refiere a la edad senil de una persona, en tanto se ubica en la última etapa de su desarrollo.

En la Primera Asamblea Mundial sobre el Envejecimiento (1982) se adoptó que una persona era considerada vieja cuando su edad era igual o superior a los 60 años. Mientras que, la Organización Mundial de la Salud (OMS, 1984) estableció el término "adulto mayor" para referirse a las personas de 60 o más años, línea que también siguió la Organización de las Naciones Unidas (1996) denominando a este grupo etario como Personas Adultas Mayores. 
La Segunda Asamblea Mundial sobre el Envejecimiento (2002) ha seguido el criterio de su antecesora. Asimismo, la Convención Interamericana sobre la Protección de los Derechos Humanos de las Personas Mayores (2015) ubica a la "Persona mayor" como aquella de 60 años o más. Sin embargo, en este documento se aclara que si el país así lo determina este límite mínimo de edad podría variar, pero que nunca superará los 65 años. Con lo cual es evidente que, si bien la denominación de la persona en la última etapa de su vida puede llegar a tener muchas acepciones, el límite inferior de edad de ésta se ha mantenido a lo largo de los años.

Dado el acelerado fenómeno de envejecimiento poblacional que atraviesa el mundo, hay quienes propenden la reclasificación de la vejez. Motivo por el cual se ha llegado a hablar de una cuarta edad, categoría que se refiere a aquellas personas mayores de 80 años Orosa (2001). Asimismo, es común que en la doctrina referida a la edad senil encontremos los términos adultos mayores jóvenes, maduros y viejos.

Para Huenchuan (2011), desde la perspectiva más habitual "el envejecimiento lleva consigo cambios en la posición del adulto mayor en la sociedad, debido a que muchas responsabilidades y privilegios, sobre todo aquellos asociados al empleo, dependen de la edad cronológica". Bajo esta consideración, se denomina adulto mayor a la persona que ha llegado a la edad de 65 años en adelante, edad en la que en la mayoría de países las personas dejan de trabajar.

Siguiendo esta línea, RAMOS (2009) considera que los adultos mayores "son aquellas personas que alcanzan una edad en la que deben abandonar formalmente el trabajo; esto hace referencia a aquella parte de la población que ha dedicado su vida a trabajar y al cabo de un tiempo debe jubilarse".

Podemos concluir este apartado señalando que usualmente una persona es denominada adulto mayor a partir de los 60 años de edad. Definición que coincide con lo previsto en la normativa de nuestro país, en donde según el artículo 2 o de la Ley de la Persona Adulta Mayor - Ley $N^{\circ} 30490$, adulto mayor es aquella persona adulta que tiene 60 o más años de edad, concepto que será utilizado a lo largo de la investigación.

\subsection{La transición demográfica en el mundo y américa latina: una población mundial que envejece}

Desde el siglo pasado el mundo viene experimentando una variación demográfica de gran nivel que se caracteriza, entre otras circunstancias, por el ascenso de la esperanza de vida al nacer y el descenso en la fecundidad (Marshall, 2017). Debido a ello la proporción de personas mayores de 60 años aumenta más rápidamente que cualquier otro grupo de edad en casi todos los países.

A mediados del siglo pasado el porcentaje de la población con más de 60 años de edad constituía el $8,1 \%$ del total mundial. Porcentaje que en 1999 aumentó a un 9,9\% y se espera que hacia el 2050 esta proporción alcance el 22,1\% (Castillo, 2011). El siglo XXI está signado por el incremento de la longevidad a nivel mundial. (Comisión Económica para América Latina y el Caribe, 2017). Según el director del Centro Latinoamericano y Caribeño de Demografía en el año 2040 las personas de 60 años o más superarán por primera vez a la población menor de 15 años, lo cual traerá consigo una nueva estructura por edad (Saad, 2017).

En América Latina y el Caribe, las personas con más de 60 años representaban el 11\% del total de la población en el año 2019. Se estima que para el año 2030 dicha población represente el 17\%. Mientras que, en el 2050 uno de cada cuatro habitantes en América Latina y el Caribe sea mayor de 60 años (Federación Iberoamericana de Asociaciones de Personas Adultas Mayores, 2019).

El Perú está envejeciendo de manera lenta pero inevitable. La población mayor de 60 años aumentará con el paso del tiempo. El incremento en la longevidad de las personas está ocurriendo en todo el país, aunque con diferentes niveles de volumen y magnitud. En el año 2010 nuestro país contaba con de 1.5 millones de adultos mayores en promedio y para el año 2050 se estima que esa cifra se incrementará a casi 6.5 millones (Plan Nacional para las personas adultas mayores, 2013). Lo cual significa que, en el lapso de 40 años, este sector de la población peruana cuadruplicaría su volumen.

Según el Instituto Nacional de Estadística e Informática (INEI, 2020), en el año 2020 son menores de 15 años, 25 de cada 100 habitantes. En Perú el incremento de la proporción de adultos mayores es notoria, ha pasado de constituir el 5,7\% de nuestra población en el año 1950 al $12,7 \%$ en el año 2020. En ese sentido, resulta también importante destacar que el INEI (2020) refirió que "del 
total de hogares del país, el 27,2\% tiene como jefe de hogar a una persona adulta mayor.".

\subsection{Marco Jurídico de protección de los adultos mayores}

\subsubsection{Convención Interamericana sobre la protección de los derechos humanos de las personas mayores}

En el año 2011, la Asamblea General de la Organización de los Estados Americanos - OEA creó un equipo de trabajo a fin de elaborar un informe sobre la situación del adulto mayor. El mismo que debía prever la efectividad de las disposiciones adoptadas hasta ese momento y el catálogo de derechos que asisten a este grupo etario. En ese escenario, el 15 de junio de 2015, se aprobó la Convención Interamericana sobre la protección de los derechos humanos de las personas mayores (Comisión Económica para América Latina y El Caribe, 2019).

Dicho instrumento jurídico constituye el primer tratado de derechos humanos de las personas mayores en el mundo. Es necesario rescatar lo previsto en el Preámbulo de la Convención Interamericana sobre la protección de los derechos humanos (2015). En él se señala que, de acuerdo a la Declaración Universal de los Derechos Humanos y a la Convención Americana sobre Derechos Humanos, para la realización de los ciudadanos se deben generar condiciones tendientes a que estos logren el ejercicio pleno de todos sus derechos.

En ese sentido, precisa que el adulto mayor tiene iguales derechos humanos y libertades fundamentales, fundados en la dignidad e igualdad inherente a todo ser humano. Estas garantías incluyen la de no verse sometido a discriminación por su edad ni a ningún tipo de violencia. Se plantea la necesidad de estudiar la vejez y el envejecimiento desde el punto de vista de los derechos humanos, reconociendo de esta manera, la valiosa contribución del adulto mayor al bienestar de las sociedades.

El Preámbulo resalta que a medida que una persona envejece, deberá seguir disfrutando de una vida plena, independiente y autónoma, con salud, seguridad, integración y participación activa en las esferas económica, social, cultural y política de sus sociedades. Fundamento que se encuentra acorde con lo que hasta el momento ha previsto la legislación de nuestro país. Se pretende un cambio de paradigma en el asunto de la vejez, eliminando los prejuicios sociales que identifican a esta etapa del desarrollo humano como de dependencia.

Ahora bien, para fines de la investigación corresponde referirnos al artículo $18^{\circ}$ de la Convención titulado "Derecho al trabajo". En este se prevé que el adulto mayor tiene derecho al trabajo digno y decente y a la igualdad de oportunidades y de trato respecto de los otros trabajadores, sin importar su edad. Como es evidente, este tratado internacional se opone a considerar la edad de una persona como único criterio para su exclusión en el mundo laboral. Por el contrario, se presenta a favor de la reinserción de este sector de la población, para lo cual considera los fundamentos que expondremos, a continuación.

Los Estados Parte adoptarán medidas para impedir la discriminación laboral de la persona mayor; es decir, se prohíbe cualquier distinción que no se base en las exigencias propias de la naturaleza del cargo. Asimismo, se prevé que el empleo o la ocupación de la persona adulta mayor deberá contar con iguales garantías, beneficios, derechos laborales y sindicales, y ser remunerado por el mismo salario aplicable a todos los trabajadores frente a iguales tareas $y$ responsabilidades.

De la lectura de estos fundamentos se colige que los adultos mayores deberán tener las mismas condiciones de empleo que los demás trabajadores. Esto es, que la distinción que pueda existir entre el trabajador de edad avanzada y los demás, se desprenda de la naturaleza del trabajo que realicen, más no de su edad. Sin embargo, ello no exime la responsabilidad del empleador de efectuar ajustes razonables y necesarios para el ejercicio del derecho al trabajo del adulto mayor.

Los Estados Parte adoptarán las medidas legislativas, administrativas o de otra índole para promover el empleo formal de la persona mayor y regular las distintas formas de autoempleo y el empleo doméstico, con miras a prevenir abusos y garantizar una adecuada cobertura social y el reconocimiento del trabajo no remunerado. Mediante esta disposición se pretende que las políticas públicas que, en materia de empleo, adopten los países, deberán venir de la mano de la implementación de medidas jurídicas que posibiliten su puesta en práctica, así como su fiscalización.

Los Estados Parte promoverán programas y medidas que faciliten una transición gradual a la jubilación, para lo cual podrán contar con la participación de las 
organizaciones representativas de empleadores y trabajadores y de otros organismos interesados.

Además, los Estados Parte promoverán políticas laborales dirigidas a propiciar que las condiciones, el ambiente de trabajo, horarios y la organización de las tareas sean adecuadas a las necesidades y características de la persona mayor. Coincidimos con esta propuesta, en tanto, la reinserción laboral de este grupo etario deberá considerar las especiales características del adulto mayor.

Los Estados Parte alentarán el diseño de programas para la capacitación y certificación de conocimiento y saberes para promover el acceso de la persona adulta mayor a mercados laborales más inclusivos. Creemos que la adopción de este criterio se ha llevado a cabo en el entendido de que la educación y el trabajo van de la mano; es evidente que una persona capacitada tendrá mayores posibilidades de insertarse al mundo laboral.

A modo de ejemplo, podríamos decir que dada la especial coyuntura que atraviesa el país, la formación en nuevas tecnologías, otorgaría un plus al trabajador. En tanto el objeto de la Convención Interamericana sobre la Protección de los Derechos Humanos es promover, proteger y asegurar el reconocimiento y el pleno goce y ejercicio, en condiciones de igualdad, de todos los derechos humanos y libertades fundamentales de los adultos mayores; la misma plantea diversos parámetros normativos coincidentes con esta investigación. Fundamentos que, además, forman parte del sustento de la investigación.

Este instrumento jurídico constituye una herramienta que obliga a los Estados a tomar acciones, a favor de la integración del adulto mayor, desde un enfoque de derechos humanos. Ha sido ratificada por muchos países, entre los cuales encontramos a Chile, Argentina, Ecuador y El Salvador. No obstante, a la fecha, nuestro país no lo ha hecho; motivo por el cual, se recomienda que el Congreso de la República apruebe esta Convención, tal y como se ha señalado en el Informe de Adjuntía N006-2019-DP/AAE (Defensoría del Pueblo, 2019).

\subsubsection{Marco jurídico nacional}

En la legislación de nuestro país, tres son los instrumentos jurídicos principales que constituyen el mejor referente de los derechos y deberes de este grupo poblacional. Estos son la Constitución Política del
Perú de 1993, la Ley de la Persona Adulta Mayor y el Reglamento de dicha ley.

La Carta Magna constituye el dispositivo legal por excelencia en nuestro ordenamiento jurídico, la misma señala en su primer artículo que la defensa de la persona humana y el respeto de su dignidad son el fin supremo de la sociedad y del Estado. En ese sentido, nuestra Constitución presenta un amplio catálogo de derechos de los cuales todas las personas, sin excepción alguna, son beneficiarias. Si bien no prevé de manera expresa disposiciones específicas para los adultos mayores, estos se incluyen tácitamente en distintos artículos de la misma.

El único artículo de la Constitución del Perú que se refiere de manera expresa a los adultos mayores, es el cuarto, el cual contempla que la comunidad y el Estado protegen especialmente al niño, al adolescente, a la madre y al anciano en situación de abandono. También protegen a la familia y promueven el matrimonio. Si bien este artículo atañe solo adulto mayor en situación de abandono, se considera que esto se debe a la data de esta norma, época en la que la longevidad de las personas no contaba con los alcances que ahora tiene.

Ahora bien, un instrumento normativo de suma importancia para este estudio es la Ley de la Persona Adulta Mayor, Ley $N^{\circ} 30490$, promulgada el 21 de julio de 2016. En su artículo $2^{\circ}$ define al adulto mayor como aquella persona de 60 años o más, concepto que coincide con lo señalado a nivel internacional.

La Ley se creó a fin de constituir un marco jurídico a favor de los adultos mayores que permita garantizar el ejercicio de sus derechos, una vida digna y su inclusión en el desarrollo social, económico, político y cultural de nuestro país. Además, promueve el envejecimiento autónomo, productivo y saludable.

La mencionada norma cuenta con 37 artículos, desarrollados sobre la base de cuatro principios: i) promoción y protección de los derechos, ii) seguridad física, económica y social, iii) protección familiar y comunitaria y v) atención de la salud centrada en la persona adulta mayor.

Sobre el particular, en la Ley de la Persona Adulta Mayor se han contemplado solo dos disposiciones específicas que se refieren al derecho al trabajo de este grupo etario. A continuación, la primera de ellas:

“Artículo 5. Derechos 
La persona adulta mayor es titular de derechos humanos y libertades fundamentales y ejerce, entre otros, el derecho a:

(...)

h) Participar activamente en las esferas social, laboral, económica, cultural y política del país."

De la lectura de este artículo, se colige el interés del legislador de incluir en el catálogo de derechos a favor del adulto mayor el que se refiere a su participación activa en el ámbito laboral. Sin embargo, incluye a este en un solo literal, junto a otras esferas de participación del ser humano. Es decir, no le otorga el tratamiento diferenciado que merece.

Otro artículo referido al derecho al trabajo del adulto mayor, es el siguiente:

\section{"Artículo 20. Atención en materia previsional, de seguridad social y empleo}

El Estado promueve una cultura previsional con la finalidad de que la persona adulta mayor acceda en forma progresiva a la seguridad social y pensiones, en el marco de lo establecido en los diversos regímenes previsionales.

Asimismo, promueve oportunidades de empleo y autoempleo productivo y formal, que coadyuven a mejorar los ingresos $y$ consecuentemente mejorar la calidad de vida de la persona adulta mayor."

Como se puede apreciar, en el segundo párrafo del artículo $20^{\circ}$ se prevé la exigencia del Estado de instar oportunidades de trabajo para los adultos mayores, considerando que el ejercicio del derecho al trabajo de este grupo poblacional traerá consigo su favorecimiento económico. Es decir, la posibilidad de subsistir en condiciones óptimas.

La Ley no considera en ninguno de sus artículos cómo garantizar el derecho al empleo del adulto mayor. Tampoco propone los mecanismos jurídicos que se deberán tener en cuenta para hacer realidad las exigencias planteadas, en el entendido de que se pretende la efectiva permanencia y reinserción de las personas de la tercera edad en el mercado laboral.

El Decreto Supremo N007-2018-MIMP, publicado el 26 de agosto de 2018, aprobó el reglamento de la ley bajo comentario. Esta norma desarrolla y precisa todas las disposiciones contenidas en la Ley $N^{\circ} 30490$, de conformidad con lo previsto en la Constitución Política del Perú y en los distintos documentos de carácter internacional que se han adoptado al respecto.

Un punto importante es que además pretende la coordinación intergubernamental e intersectorial, y establece competencias específicas a distintas carteras ministeriales, tales como el Ministerio de Educación y el Ministerio Trabajo y Promoción del Empleo.

Como se aprecia, las normas que regulan al adulto mayor en el Perú centran su atención en la integración y participación de este sector de la población en el desarrollo de nuestro país. Asimismo, creemos que pretenden eliminar los prejuicios que asocian a la vejez con la pérdida de capacidades físicas y mentales, a fin de que el adulto mayor sea visto con un ciudadano que pueden continuar siendo productivo y que tiene aún mucho que aportar.

Ahora bien, el Decreto Supremo N007-2018-MIMP, que aprueba el Reglamento de la Ley bajo comentario, plantea lo siguiente:

\section{Artículo 11.- Centros Integrales de Atención al Adulto Mayor}

11.3 Acciones de coordinación y articulación para el funcionamiento de los CIAM

Los CIAM para su adecuado funcionamiento coordinan y articulan con las instituciones públicas y privadas siguientes:

(...)

f) Con el Ministerio de Trabajo y Promoción del Empleo: La promoción de la no discriminación por edad en materia laboral, las mejoras en las condiciones de empleabilidad, reinserción laboral y todo trato favorable en el ámbito laboral para las personas adultas mayores.

Este artículo del Reglamento se muestra también a favor de la propuesta de este estudio. Como vemos, se refiere a la optimización de la empleabilidad de la población adulta mayor, así como a su reinserción en el empleo y al trato adecuado que se le debe brindar.

\section{"EN MATERIA SEGURIDAD SOCIAL Y EMPLEO}

Artículo 34.- Promoción de oportunidades de empleo y autoempleo productivo y formal

El Estado, en sus tres niveles de gobierno, promueve, capacita, gestiona y crea oportunidades de empleo, autoempleo productivo y formal, así como emprendimientos productivos para personas adultas mayores de acuerdo a su experiencia de vida, condición de salud y respeto a su 
autonomía. En este sentido se debe garantizar lo siguiente:

a) Prohibir la discriminación laboral por razones de edad.

b) Prohibir cualquier distinción, que no se base en las exigencias propias de la naturaleza de la función a realizar, en todos los regímenes laborales.

c) Proveer las mismas garantías, beneficios, derechos laborales y sindicales y ser remunerado con el mismo salario aplicable a todos/as los/las trabajadores/as frente a iguales funciones y responsabilidades.

d) Promover políticas laborales dirigidas a propiciar que las condiciones, el ambiente de trabajo, horarios y la organización de las funciones sean adecuadas a las características de las personas adultas mayores.

e) Cualquier otra medida que favorezca a los intereses de la persona adulta mayor."

Se considera que el Reglamento efectivamente desarrolló la Ley, en el sentido que otorgó un mayor tratamiento a la inserción laboral del adulto mayor. Incluso contempló el deber de seguir 5 parámetros a fin de promover la igualdad y prohibir la discriminación en las oportunidades laborales. Sin embargo, tampoco encontramos en las disposiciones del Reglamento la propuesta de mecanismos para efectivizar la política de acceso al trabajo.

\subsection{Problemática del adulto mayor: Pensiones y empleo}

La población adulta mayor en Perú enfrenta una serie de problemas, entre ellos, los referidos a la salud, educación e inclusión social. Sin embargo, por ser de mayor interés en el desarrollo de la investigación, nos referiremos solo a dos de ellos, estos son el acceso a una pensión y el acceso al empleo de este grupo etario.

\subsubsection{Acceso a una pensión}

El derecho a la seguridad social se encuentra constitucionalmente reconocido, en los artículos $10^{\circ} \mathrm{y}$ $11^{\circ}$ de nuestra Carta Fundamental. En los cuales se señala que el Estado reconoce el derecho universal y progresivo de toda persona a la seguridad social, que lo protejan ante cualquier contingencia y aseguren una vida digna durante su vejez. Asimismo, confirma el libre acceso a pensiones. A nivel internacional, la Declaración Universal de los Derechos Humanos en su artículo $22^{\circ}$ reconoce el derecho a la seguridad social como derecho fundamental.
Es necesario considerar que en nuestro país coexisten dos sistemas pensionarios. Por un lado, encontramos al Sistema Público de Pensiones, dentro del cual se encuentra el Sistema Nacional de Pensiones, creado por el Decreto Ley N¹9990 y el denominado Cédula Viva, regulado por el Decreto Ley $N^{\circ}$ 20530. Mientas que, el Sistema Privado de Pensiones, regulado por la Ley $N^{\circ} 29903$, es administrado por las Administradoras de Fondos de Pensiones.

Según la Encuesta Nacional de Hogares - ENAHO del año 2017, 6 de cada 10 personas de 60 años y más de edad no recibieron ningún tipo de pensión contributiva (Defensoría del Pueblo, 2019). Del total de esta población, solo el $38,6 \%$ se encuentra afiliado a un sistema pensionario, ya sea público o privado. Hasta el primer trimestre de 2020, el 20,0\% está afiliado a la Oficina de Normalización Previsional (ONP), el 11,4\% de afiliados a las Administradoras de Fondos de Pensiones (AFP) y el 4,0\% a la Cédula viva (INEI 2020).

Las cifras mencionadas resultan alarmantes, dado que nos llevan a concluir que el 61,4\% del total de adultos mayores se encuentran desprotegidos, al no estar afiliados a ningún sistema de pensión contributiva que los respalde económicamente en cuanto dejen de trabajar. Se suma a esta situación que afecta a más de la mitad de este grupo etario, el hecho de que, en la mayoría de los casos, el monto de la pensión que reciben quienes sí cuentan con una, es insuficiente para satisfacer sus necesidades y garantizar una vida digna en la vejez.

Como respuesta al problema de pobreza extrema que aqueja a la población adulta mayor en nuestro país, se promulgó el Decreto Supremo N081-2011-PCM, mediante el cual se creó el Programa Nacional de Asistencia Solidaria, conocido como "Pensión 65". A través de él, el Estado presta apoyo económico a personas de 65 años a más que se encuentren en extrema pobreza, tras cumplir una serie de requisitos contemplados en dicho dispositivo legal. Esta pensión no contributiva corresponde a un monto de $\mathrm{S} / 250.00$ entregados de forma bimestral.

Al respecto, el INEI (2020) refirió que "en el primer trimestre de 2020, el $14,6 \%$ de los jefes/as de hogar de la población adulta mayor se beneficiaron del programa social Pensión 65. Según área de residencia, los jefes de hogar del Área rural se beneficiaron en mayor proporción $(43,1 \%)$ que los jefes de hogar del Área urbana $(6,1 \%) . "$. Lo cual denota que del cálculo de los adultos mayores afiliados a un sistema previsional y de 
aquellos que reciben apoyo del programa Pensión 65, aún un gran porcentaje de esta población se encuentra en total desprotección.

\subsubsection{El adulto mayor en el mercado laboral peruano}

Es evidente que el incremento de la longevidad plantea el escenario de la disminución del número de personas en edad laboral frente al aumento de personas adultas mayores, con una esperanza de vida superior a la de hace algunos años. Ello repercutirá en el mercado laboral, en tanto habrá personas que trabajen más años de los imaginados, no solo porque necesitarán el dinero para subsistir, dada la ausencia o escasos montos pensionarios, sino también porque aún se sienten capaces de continuar o de reinsertarse en la vida laboral.

En este apartado se expondrán las tasas de participación laboral del adulto mayor en el Perú. Es preciso indicar que la celeridad en la transición de la estructura demográfica del mundo sugiere la adopción de acciones que permitan a los países afrontar este reto, que se traduce en los requerimientos de este sector de la población, en distintos ámbitos, que, desde luego, incluyen al laboral.

En el Informe Mundial sobre el Envejecimiento y la Salud se señala que es muy común que los empleadores presenten actitudes de rechazo hacia los trabajadores de avanzada edad, aunque éstos no necesariamente sean menos saludables, educados, habilidosos o productivos que sus colegas más jóvenes (OMS, 2015). Asimismo, defiende la idea de que la edad no es un criterio objetivo al momento de evaluar la empleabilidad y/o el nivel productivo de una persona.

Se considera necesario incluir a los trabajadores de edad avanzada en la fuerza laboral. Para lo cual, se propone que se otorgue mayor relevancia a la educación y capacitación de este sector poblacional, con lo cual se incrementará su productividad (Cardona, 2012). En ese sentido, para el aumento de la participación laboral de los trabajadores mayores, se debe incidir en las siguientes áreas: (i) extender la vida productiva, aumentando la de la edad de jubilación; (ii) incrementar la cantidad de trabajadores de edad y (iii) aumentar la productividad de los mismos (Murrugara, 2011).

En Perú, los adultos mayores que están incluidos en la Población Económicamente Activa - PEA, ya sea que se encuentren trabajando o buscando un empleo, constituyen el 55,4\%. Mientras que, los adultos mayores que no forman parte de la PEA, constituyen el
44,6\% (INEI, 2020). Estas cifras revelan que casi la mitad del total de la población adulta mayor no cuenta con un empleo que le permita subsistir en la vejez, lo que, en contraste con las cifras de acceso a una pensión, revela que alrededor del $50 \%$ de adultos mayores en nuestro país no cuentan con ningún ingreso económico.

En este contexto, las estadísticas sobre empleo muestran que, de cada 10 personas de 60 a más años de edad, aproximadamente, 6 de ellas participan en el mercado laboral, como ocupadas o desocupadas; mientras que, las restantes 4 personas mayores representarían la denominada población económicamente inactiva. Las circunstancias en las que los adultos mayores trabajan no serían las apropiadas, dado que, el $53,5 \%$ de esta población son trabajadores independientes (INEI, 2020).

Este último punto nos lleva a concluir que, al no tener acceso al mercado laboral formal, el adulto mayor toma la decisión de emplearse en trabajos informales, en los cuales no pueden acceder a un seguro de salud y/o previsional. Pese a ello, nuestro país aún no cuenta con un Plan de Promoción del Empleo para Personas Adultas Mayores, avance que resultaría de gran importancia en el ámbito laboral de este grupo etario.

En concordancia con el escenario planteado, la Ley de la Persona Adulta Mayor y su Reglamento, han previsto en sus disposiciones la exigencia al Estado de promover oportunidades de empleo y autoempleo productivo y formal, con el objetivo de mejorar los ingresos $y$, consecuentemente, la calidad de vida de las personas adultas mayores. Sin embargo, en las mencionadas normas no se han considerado los criterios a tomar en cuenta para hacer posible dicha obligación ni las medidas de fiscalización.

El empleo de la persona adulta mayor es un tópico que genera tesis a favor y en contra. Por un lado, se prioriza el derecho-deber a gozar del descanso tras una vida laboral, entendido como la jubilación. Mientras que, por otro, se reconoce que la mayoría de adultos mayores cuenta con una pensión irrisoria o nula, y enfrenten el problema del desempleo.

Esta última tesis cobra mayor sentido en la actualidad, en el entendido de que la esperanza de vida sigue en aumento y el incremento en la longevidad de la población peruana no cesa. Motivo por el cual resulta imperativo que, tal y como se señala en la legislación pertinente, el Estado fomente la empleabilidad de este sector poblacional. Con lo cual además se promueve la 
independencia y autonomía económica de los adultos mayores, a fin de garantizar un envejecimiento activo $y$ saludable.

\section{La reinserción laboral del adulto mayor como política pública}

Nuestro país, aunque con diferentes grados de volumen e intensidad, atraviesa un inexorable fenómeno de envejecimiento. El grupo de personas de 60 y más años de edad, consideradas adultos mayores por la legislación nacional, se incrementará sostenidamente en las próximas décadas. Situación que generará desafíos y exigencias de diferente naturaleza, en términos de implementación de políticas públicas en todos los ámbitos.

En el presente apartado se hará una breve revisión de las políticas públicas que promueve el Estado peruano a favor de este grupo poblacional. Empezaremos con las nacionales, como el Acuerdo Nacional 2016 - 2021, hasta llegar a las políticas regionales, en donde encontramos al Plan Desconcertado del Gobierno Regional de Lambayeque. Asimismo, se verificará si en las disposiciones de los instrumentos utilizados en el presente apartado se contemplan la reinserción y permanencia laboral del adulto mayor como objetivos.

\subsection{El adulto mayor en el Acuerdo Nacional del Perú: Políticas de Estado y Planes de Gobierno 2016 - 2021}

En el año 2002, durante el Gobierno del ex presidente Alejandro Toledo, se inició el proceso de elaboración del Acuerdo Nacional del Perú. Este instrumento serviría como base en la transición hacia la consolidación de la democracia, afirmación de la identidad nacional y el diseño de una visión compartida del país a futuro, a través de la formulación de 31 políticas de Estado (Alarco, 2010). Esta iniciativa propuso que las metas y objetivos trazados en dicho Acuerdo deberían permitir, a través de criterios de evaluación, que los actores políticos y la sociedad contrasten su desempeño.

El Acuerdo Nacional marcó un hito en la historia de nuestro país, dado que este representa un esfuerzo colectivo para construir la nación que todos los peruanos anhelamos (Trivello, 2014). En él se han aprobado 31 Políticas de Estado, que constituyen pautas orientadoras para la construcción de los objetivos nacionales, las políticas, metas y acciones incluidos en el Plan Bicentenario: El Perú hacia el 2021.
Las referidas políticas han sido agrupadas en cuatro ejes temáticos:

- Democracia y Estado de Derecho.

- Equidad y Justicia Social.

- Competitividad del país.

- Estado eficiente, transparente y descentralizado.

De acuerdo con el artículo 1 으 de la Constitución peruana la defensa de la persona humana y el respeto de su dignidad son el fin supremo de la sociedad y del Estado. En ese sentido, lo que propone el Plan Bicentenario es un método estratégico de desarrollo nacional, que considera al ejercicio universal de los derechos fundamentales el fin de toda sociedad humana. Sus cuatro ejes temáticos definen lineamientos generales que pretenden un desarrollo inclusivo, equitativo, sostenible y a efectos de afirmar la gobernabilidad democrática en el país.

El estado peruano tiene como objetivo principal la democracia, en la cual prevalezca el Estado de derecho y se garantice la igualdad de oportunidades. Con ello se busca desarrollar nuestro máximo potencial como seres humanos, teniendo en cuenta que el respeto de nuestra dignidad humana no admite discriminación. Este enfoque ha sido adoptado en el Acuerdo Nacional, al instar el cumplimiento de los objetivos planteados en sus ejes temáticos para convertirse en una sociedad con pleno ejercicio y respeto de los derechos humanos de todos sus ciudadanos, especialmente de aquellos que pertenecen a las poblaciones vulnerables (Acuerdo Nacional del Perú, 2016).

Entonces, corresponde revisar lo que esta política plantea en relación con lo propuesto en este estudio. Para lo cual tendremos en cuenta que, en su segundo eje temático, esta política nacional defiende la idea de Equidad y Justica Social, dentro de la cual plantea como meta que en nuestro país todos los ciudadanos tengamos acceso al empleo digno y productivo.

Uno de sus objetivos es el de economía competitiva con alto nivel de empleo y productividad. Este plantea como meta una economía dinámica y diversificada, integrada competitivamente a la economía mundial y con un mercado interno desarrollado, en un marco de reglas estables que promuevan la inversión privada con alta generación de empleo y elevada productividad del trabajo. Siendo así, este objetivo prevé el lineamiento "Empleo", en el cual se plantea que el estado peruano pretende promover el acceso de las mujeres, los jóvenes, los adultos mayores y los discapacitados a los mercados de trabajo (Acuerdo Nacional del Perú, 2016). 
En específico, el objetivo en mención está incluido en la Política de Estado №14 y se denomina "Acceso al empleo pleno, digno y productivo", el mismo que tiene las siguientes metas: (i) procurar las condiciones y oportunidades para la generación de empleo dependiente a través del dinamismo de la inversión y auto empleo a través del desarrollo del emprendimiento con capacidades; (ii) promover mecanismos que permitan el uso adecuado de los beneficios estatales para todos y todas; $y$ (iii) promover el acceso al empleo de sectores vulnerables como jóvenes, en especial mujeres jóvenes, personas con necesidades especiales, adultos mayores, etc. (Acuerdo Nacional del Perú, 2016).

A fin de lograr el "Acceso al empleo pleno, digno y productivo", el Perú deberá efectuar las siguientes estrategias: (i) La promoción de la igualdad de oportunidades sin discriminación; (ii) establecer cuotas de empleabilidad laboral tanto en el sector público como privado a nivel calificado como no calificado de mujeres, jóvenes, personas con discapacidades, personas mayores y poblaciones indígenas. Asimismo, deberá (iv) implementar el Viceministerio del Adulto Mayor, adscrito al Ministerio de la Mujer y Poblaciones Vulnerables.

En relación al fomento de la inserción laboral de este grupo etario se ha previsto la creación del programa "De vuelta a la Cancha", a fin de brindar capacitación para pasantías de los adultos mayores en empresas privadas. Asimismo, a efectos de mejorar la situación económica del adulto mayor trabajador, se plantea la coordinación con los gobiernos locales que faciliten asistencia técnica mediante el cofinanciamiento; así como la creación de programas de capacitación ocupacional que incluyan bolsas de trabajo para personas adultas mayores (Acuerdo Nacional del Perú, 2016).

Aunado a ello se establece que la educación de todos los ciudadanos es un tema de preocupación para el Perú. En ese sentido, la población adulta mayor también se beneficiará de ello, para lo cual se propone trabajar con los gobiernos locales para implementar el programa alfabetización para personas adultas mayores de zonas alto-andinas y amazónicas; promover el acceso a educación técnica y universitaria, siendo prioritario adaptar el uso de herramientas informáticas a las condiciones de las personas de avanzada edad.

\subsection{El adulto mayor en el Plan Nacional de Derechos Humanos 2018-2021}

Mediante Decreto Supremo N002-2018-JUS se aprobó el Plan Nacional de Derechos Humanos 2018-2021. Dicho instrumento consta de cinco lineamientos estratégicos: (i) promoción de una cultura de derechos humanos y la paz en el Perú; (ii) diseño y fortalecimiento de la política pública de promoción y protección de los derechos civiles, políticos, económicos, sociales, culturales y ambientales; (iii) diseño y ejecución de políticas a favor de los grupos de especial protección; (iv) fortalecimiento del ordenamiento jurídico interno, a través de la implementación de instrumentos internacionales para la promoción y protección de los derechos humanos; e (v) implementación de estándares internacionales sobre empresas y derechos humanos (Blouin, 2018).

En el Lineamiento Estratégico $\mathrm{N}^{\circ} 3$ denominado "Diseño y ejecución de políticas a favor de los grupos de especial protección", se prevé el Objetivo Estratégico $N^{\circ} 1$, destinado a garantizar y promover la autonomía e independencia de los adultos mayores, mejorando la calidad de vida y el pleno ejercicio de sus derechos. Este objetivo adopta distintas acciones estratégicas, la cuarta de ellas es de interés de este estudio, dado que persigue la promoción de condiciones de empleabilidad para el acceso al mercado laboral de las personas adultas mayores, propiciando mejoras en su calidad de vida (Plan Nacional de Derechos Humanos 2018-2021, 2018).

Para hacer efectiva la mencionada acción estratégica, se deberán fortalecer las oportunidades de las personas adultas mayores que voluntariamente formalicen su deseo de incorporarse al mercado laboral. Asimismo, se necesitarán espacios para la reinserción ocupacional de las personas de tercera edad, a través de empleos temporales, los mismos que deberán considerar las características peculiares de las personas de edad avanzada.

También resulta importante ejecutar medidas de políticas públicas orientadas a promover el empleo productivo y formal y la participación laboral de las personas adultas mayores. Ello en aras a propiciar su autonomía y autorrealización, valorando sus conocimientos y contribución a la sociedad. Se tiene como meta que, para el año 2021, exista un Plan de Promoción del empleo para personas adultas mayores, a cargo del Ministerio de Trabajo y Promoción del Empleo.

\subsection{Análisis del Plan Nacional de Personas Adultas Mayores 2013-2017}


Desde el 16 de junio de 2013 nuestro país cuenta con un Plan Nacional de Personas Adultas Mayores 2013 2017. Este instrumento, aprobado mediante Decreto Supremo N002-2013-MIMP, surgió con el fin de beneficiar a las personas adultas mayores del Perú. El Plan fue elaborado por el Ministerio de la Mujer y Poblaciones Vulnerables, a través de la Dirección de Personas Adultas Mayores, y plantea cuatro políticas esenciales, con el fin de promover para este sector de la población una adecuada gestión intersectorial, intergubernamental e interinstitucional por el envejecimiento activo y saludable.

Se presenta un marco conceptual basado en una concepción del envejecimiento como proceso. El cual inicia en el nacimiento de la persona y que, en sí mismo, constituye hoy en día uno de los mayores logros de la humanidad. Además, establece para el criterio de vejez desde el punto de vista cronológico la edad de 60 años a más, como determinante de las personas adultas mayores, posición asumida en el presente estudio. Esta política peruana se ha elaborado bajo los enfoques básicos que orientan la acción del sector: de derechos humanos, de igualdad de género, de interculturalidad, así como el enfoque intergeneracional (Plan Nacional de Personas Adultas Mayores, 2017).

El citado documento tiene como objetivo general mejorar la calidad de vida de las personas adultas mayores. Para lo cual se pretende la satisfacción integral de sus necesidades, su participación activa y la promoción de sus derechos, desarrollando intervenciones articuladas entre los distintos niveles del Estado y la Sociedad Civil (Plan Nacional de Personas Adultas Mayores, 2017). Siguiendo este enfoque, a continuación, se desarrollan los lineamientos de dicho instrumento jurídico.

En primer lugar, el envejecimiento saludable. Lineamiento que busca mejorar el bienestar físico, psíquico y social de las personas adultas mayores, a través del incremento en la cobertura y calidad de los servicios socio-sanitarios, la garantía de una asistencia alimentaria y nutricional, y la generación de oportunidades para una vida armónica dentro de su familia y su comunidad.

En segundo lugar, el empleo, previsión y seguridad social. Mediante esta directriz se pretende promover oportunidades de empleo para las personas adultas mayores, a través de mecanismos que permitan mejorar su calificación e inserción en el mercado laboral. Asimismo, se garantiza un nivel mínimo de ingresos y su acceso a los servicios de previsión y seguridad social.

En tercer lugar, se encuentra la participación e integridad social. Por medio de esta pauta se persigue el incremento en los niveles de participación social y política de las personas adultas mayores de manera que la sociedad los integre como agentes del desarrollo comunitario.

Y finalmente, como cuarto eje, encontramos el de Educación, conciencia y cultura sobre el envejecimiento y la vejez. El cual tiene como finalidad elevar el nivel educativo y cultural de la población adulta mayor, promover una imagen positiva del envejecimiento y la vejez e incrementar en la sociedad el reconocimiento hacia los valores y experiencia de vida de las personas adultas mayores.

Como se ha señalado, dentro de los lineamientos del acotado Plan, encontramos el referido al "Empleo, previsión y seguridad social", éste considera al envejecimiento como un proceso natural inherente a todo ser vivo. En ese sentido, resulta importante que la política nacional en materia de empleo, previsión y seguridad social, no concentre su atención en las actuales generaciones adultos mayores. Sino que, de cara al futuro, promuevan la necesidad de hacer frente a la vejez en adecuadas condiciones, con el propósito de lograr un envejecimiento digno, activo y saludable.

El referido lineamiento tiene como fin la promoción de oportunidades para las personas adultas mayores mediante mecanismos que permitan mejorar su calificación e inserción en el mercado laboral garantizando un nivel mínimo de ingresos y su acceso a los servicios de previsión y seguridad social. Así como promover el acceso a los servicios de mejora de la empleabilidad de hombres y mujeres adultas mayores, de acuerdo a su experiencia, sus intereses, capacidades y demanda laboral. Además, se coordinará la implementación de programas de micro emprendimiento y comercialización de sus productos para la población adulta mayor (Plan Nacional de Personas Adultas Mayores, 2017).

El empleo y aseguramiento de los adultos mayores constituyen los mayores retos para aquello países con poblaciones en proceso de envejecimiento. Razón por la que el Perú ha elaborado el Plan Nacional al que venimos haciendo referencia. Instrumento en el cual se señala que es el Ministerio de la Mujer y Poblaciones Vulnerables, en coordinación con las entidades públicas 
sectoriales, el ente encargado de promover oportunidades laborales para las personas adultas mayores.

\subsection{El adulto mayor en el Plan de Desarrollo Regional Concertado de Lambayeque 2011 - 2021}

El Plan de Desarrollo Regional Concertado de Lambayeque 2011-2021, creado en el año 2011, asume dentro de su visión al 2021 que Lambayeque será una sociedad integrada con identidad propia. Además, desde la perspectiva del ejercicio de derechos e igualdad de oportunidades, pretende garantizar el acceso a servicios sociales básicos, la consolidación de una gestión pública eficiente (Plan de Desarrollo Regional Concertado de Lambayeque 2011-2021, 2011).

Para tal efecto ha incluido cuatro ejes estratégicos: el primero que promueve la inclusión e integración socio cultural y acceso a servicios básicos; el segundo, ligado a la competitividad económica-productiva e innovación; el tercero, relacionado a la gobernabilidad $y$ fortalecimiento de la gestión pública; y el cuarto, relacionado a la gestión adecuada y sostenible del territorio y del ambiente (Plan de Desarrollo Regional Concertado de Lambayeque 2011-2021, 2011).

La población de Lambayeque se constituye por 1'398,800 habitantes, y continúa siendo mayoritariamente joven, entre 15 a 24 años de edad. Sin embargo, muestra una tendencia al envejecimiento, dada la baja fecundidad alcanzada y alta migración en los últimos 15 años. En ese sentido, los Gobiernos Regionales, en el marco de sus competencias, se encargan del: a) Registro de Organizaciones de Personas Adultas Mayores; y del b) registro de Instituciones que desarrollan Programas, Proyectos y otras actividades a favor de las personas adultas mayores de su jurisdicción (Plan de Desarrollo Regional Concertado de Lambayeque 2011-2021, 2011).

El citado documento plantea como eje estratégico No01, la "Inclusión e integración socio cultural y acceso a servicios sociales básicos". Además, tiene como objetivo estratégico №02 que la sociedad lambayecana en su diversidad logre mayores niveles de inclusión, integración e identidad socio cultural, en el marco de los derechos y obligaciones de los ciudadanos, facilitando una mayor participación en la vida social, económica y política de mujeres y hombres (Plan de Desarrollo Regional Concertado de Lambayeque 2011-2021, 2011).
En este último objetivo se incluye la política de empleo, a fin de promover mayores oportunidades de generación de trabajo digno con igualdad de oportunidades y equidad de género. Queda entonces claro que es en este eje en el que se puede situar la reinserción laboral del adulto mayor. En específico, la política de empleo pretende garantizar el acceso de las mujeres, jóvenes, adultos mayores, y personas discapacitadas al mercado laboral con igualdad de oportunidades y equidad de género.

Se han previsto como programas y proyectos los siguientes: "Desarrollo de capacidades para la reconversión de la oferta educativa de los Institutos Superiores del departamento de Lambayeque", "Programa de Fortalecimiento de capacidades de la población femenina de escasos recursos en oficios de demanda regional", "Proyecto de formación profesional", "Programa de igualdad de oportunidades dirigido a personas de sectores vulnerables (hombres y mujeres) excluidos socialmente (discriminados)" e "Implementación de políticas sobre migración laboral." (Plan de Desarrollo Regional Concertado de Lambayeque 2011-2021, 2011).

A modo de conclusión, corresponde señalar que, pese a haberse planteado en sus objetivos, el documento en comentario no prevé ningún programa o proyecto específico a favor de la reinserción o permanencia laboral del adulto mayor en Lambayeque. Aunque no es lo ideal, se podría incluir a esta población dentro del "Programa de igualdad de oportunidades dirigido a personas de sectores vulnerables (hombres y mujeres) excluidos socialmente (discriminados)".

\section{Medidas jurídicas específicas para la reinserción y permanencia del adulto mayor en el empleo: una tarea pendiente}

En este capítulo proponemos medidas jurídicas específicas, mediante las cuales se puedan hacer efectivas las políticas públicas en el Perú, dirigidas a la reinserción y permanencia laboral de los adultos mayores, al tornarse necesario brindar una atención eficaz a este grupo poblacional. Antes se torna necesario revisar algunos apuntes jurisprudenciales sobre la edad del trabajador como criterio que determina la continuidad de una relación laboral. 


\subsection{La edad como causal de término de la relación laboral: Caso Ley Universitaria}

En Perú existen distintos regímenes laborales que consideran la edad del trabajador como una causal de término de la relación de trabajo. A modo de ejemplo, tenemos a la Ley $N^{\circ} 30057$ - Ley del Servicio Civil, al Texto Único Ordenado del Decreto Legislativo N728 Ley de Productividad y Competitividad Laboral y al Decreto Legislativo $N^{\circ} 276$, dispositivos jurídicos que han establecido como límite de edad para el cese de la relación laboral los 70 años. Mientras tanto, la Ley №29944 - Ley de Reforma Magisterial, señala que el retiro de la Carrera Pública Magisterial, por límite de edad, se produce a los 65 años.

En ese orden de ideas se hace necesario exponer, de manera breve, la controversia surgida por el cuarto párrafo del artículo $84^{\circ}$ de la Ley Universitaria, Ley N³0220, publicada en el Diario Oficial "El Peruano" el 9 de julio de 2014. Mediante esta norma se consideró que para el ejercicio de la docencia y de los cargos administrativos en las universidades públicas, el límite de edad de los docentes sería los 70 años. Superada esta edad, los docentes podrían seguir enseñando solo en condición de extraordinarios, categoría que no puede exceder el $10 \%$ total de profesores en un semestre.

La crítica a la citada Ley se centra en el desacuerdo con la idea de considerar la edad del docente como criterio para decidir si éste continúa o no ejerciendo la docencia en las universidades públicas. Dado que, al cumplir los 70 años si no se le categoriza como profesor extraordinario, le corresponderá cesar. Tanto en la actividad privada como en la pública, si la legislación prevé la extinción de la relación laboral por edad máxima, se presume la incapacidad del trabajador (Neves Mujica, 2010). Esta situación es la que se presenta en el artículo $84^{\circ}$ de la Ley Universitaria.

En ese sentido, el Tribunal Constitucional se ha pronunciado en múltiples ocasiones, sobre la edad del trabajador como criterio que determina el término de una relación laboral. A modo de ejemplo citaremos las siguientes sentencias:

\section{Sentencia recaída en el expediente $N^{\circ}$ 594-99- AA/TC:}

“(...) habiéndose acreditado en autos la decisión de cesar al demandante por límite de edad (70 años), se han vulnerado los derechos constitucionales relativos al trabajo y a la protección adecuada contra el despido arbitrario, ya que por razones de edad se estaría privando a un docente de ejercer la cátedra universitaria, cuando es evidente que el solo hecho de llegar a una edad determinada, no disminuye necesariamente las aptitudes que se requieren para el ejercicio de las labores propias de un académico; o de desarrollar funciones administrativas que viene cumpliendo así como las de alta dirección que por ley le corresponde en el ámbito de sus responsabilidades académicas, que se le puedan encargar (...)". (STC 594-99AA/TC del 10 de diciembre de 1999, fundamento jurídico cuarto).

Sentencia recaída en el expediente $N^{\circ} 01875$ 2006-PA/TC:

“(...) Lo que es contrario al derecho de igualdad es imponer una limitación general fundada exclusivamente en la edad, a pesar de que el artículo 18ㅇ de la Ley №28091 dispone que la edad para pasar al retiro es de 70 años, sin considerar criterios objetivos. (...)".

Asimismo, en el fundamento vigésimo sétimo defiende que "(...) la imposición de la limitación de que puedan ocupar cargos en órganos de línea en el Ministerio de Relaciones Exteriores y cargos permanentes en el exterior, fundándose solamente en su edad, constituye un acto de discriminación directa por razón de edad en relación a otros funcionarios diplomáticos de menor edad. Por las mismas razones, tales normas constituyen una amenaza cierta e inminente de violación del derecho constitucional a la igualdad de los demás demandantes que aún no cumplen sesenta y cinco años de edad". (STC 018752006-PA/TC del 05 de junio de 2006, fundamento vigésimo quinto).

Concordamos con lo señalado por el Tribunal Constitucional, en el sentido de que el factor edad de manera aislada no debería significar un criterio objetivo a tomar en cuenta para la culminación de una relación laboral. La capacidad de una persona para acceder o permanecer en un puesto de trabajo depende de distintos factores, tanto intelectuales como físicos. No podemos entonces pretender que llegar a la tercera edad constituya un criterio determinante para la extinción de una relación laboral. Máxime si, como hemos venido señalando, no todos los seres humanos envejecemos de la misma forma, al ser esta una etapa polifacética. 
A pesar de los prejuicios que giran en torno al asunto del envejecimiento, es evidente que no todos los adultos mayores se encuentran en situación de fragilidad y/o dependencia. Sino que, por el contrario, las cifras han demostrado que en nuestro país un alto porcentaje de esta población continúa trabajando y son jefes de hogares. Es un hecho que el envejecimiento puede también afrontarse positivamente y que los adultos mayores en condiciones óptimas de salud pueden continuar su vida laboral, ya sea por razones económicas o personales.

En el caso en particular, coincidimos en el hecho de que, al ser el ejercicio de la docencia un servicio público, el desempeño de los profesores debe evaluarse, considerando sus méritos académicos. Lo cual incluye la producción científica, lectiva y de investigación, tal y como lo establece el segundo párrafo del artículo $84^{\circ}$ de la ley bajo comentario. Sin embargo, creemos que este examen debe realizarse permanentemente a todos los docentes, indistintamente de la edad que tengan.

Cabe resaltar que la Ley Universitaria ha sido objeto de cuatro demandas de inconstitucionalidad, con distintos cuestionamientos. Entre los que figura el que nos atañe, a disconformidad con el cuarto párrafo de su artículo $84^{\circ}$. Si bien, el Tribunal Constitucional mediante sentencia de fecha 10 de noviembre de 2015, recaída en los expedientes $\mathrm{N}^{\circ} 0014-2014-\mathrm{P} 1 / \mathrm{TC}, 0016$ 2014-PI/TC, 0019-2014-P1/TC y 0007-2015-PI/TC, ha confirmado la constitucionalidad de esta norma, hubo dos votos singulares con argumentos relevantes para la presente investigación.

El Magistrado Miranda Canales (2015), refirió lo siguiente:

\section{"(...)}

3. Como se desprende de las citadas disposiciones, la ley universitaria restringe la participación de los profesores universitarios de más de 70 años.

4. Al respecto, considero que, si bien esta limitación persigue una finalidad constitucionalmente legítima, esto es, mejorar la calidad de la educación, lo cierto es que la edad, por sí misma, no constituye el único criterio adecuado para evaluar el rendimiento de un docente universitario, puesto que la calidad de la enseñanza no necesariamente, está relacionada con la edad del docente. En efecto, ningún profesor universitario es bueno o malo por la edad que tenga sino por una serie de factores como son los grados académicos obtenidos, la actividad investigadora desarrollada a lo largo de su carrera, sus publicaciones, entre otros.

5. Además, la propia ley prevé de otros mecanismos destinados a asegurar la calidad de los docentes, que resultan mucho más adecuados para tal fin, y que no toman en cuenta la edad como parámetro. Así, el propio artículo 84 de la ley prevé en su primer párrafo que los docentes serán sometidos a un proceso de ratificación periódico cada 3, 5 o 7 años, dependiendo de si se trata de profesores auxiliares, asociados, y principales, respectivamente.

6. De este modo, ante la existencia de otros mecanismos - ya previstos en la propia ley que resultan más adecuados para evaluar el desempeño profesional de los docentes universitarios, y que a su vez son menos restrictivos del derecho al trabajo que a limitación por edad, determina la inconstitucionalidad del cuarto párrafo del artículo 84 de la Ley Universitaria."

Por otro lado, el Magistrado Ernesto Blume Fortini (2015), expuso los siguientes argumentos:

\section{“(...)}

9.2 Dije al respecto que el obligar a que un docente se retire únicamente en función de la edad que tiene constituye un despropósito y sobre todo un acto contrario a lo dispuesto en el inciso 2 del artículo $2^{\circ}$ de la Constitución, que recoge corno uno de los derechos fundamentales el de la igualdad y prohíbe la discriminación por motivos de toda índole, preceptuando que toda persona tiene derecho:

"A la igualdad ante la ley. Nadie debe ser discriminado por motivo de origen, raza, sexo, idioma, religión, opinión, condición económica o de cualquiera otra índole."

9.3 Debe recordarse al respecto que la docencia no es una actividad en la que se prioriza la condición física óptima, sino más bien las condiciones mentales y la capacidad intelectual, habida cuenta que son estas últimas las que permiten una adecuada trasmisión de los contenidos de las diversas asignaturas que se imparten en el proceso de 
aprendizaje; en este caso universitario o superior.

(...)

9.5 Por ello, pretender que el correcto aprendizaje en el ámbito universitario se garantiza per se porque un docente tiene menos de la edad que la prevista por la norma impugnada, es partir de una presunción que admite prueba en contrario, pues no existe dato objetivo alguno que demuestre que, porque un profesor tiene menos edad que otro, el proceso de enseñanza resulte más óptimo. Al contrario de ello, la experiencia ganada con los años acrecienta las posibilidades de una mejor aptitud docente y de una mejor calidad del proceso de aprendizaje y de la trasmisión de conocimiento.

(...)

11.16 Considero que el artículo $84^{\circ}$ de la norma impugnada, referido al periodo de evaluación para el nombramiento y cese de los profesores ordinarios, es igualmente inconstitucional, particularmente en lo referido al cese automático de los docentes pertenecientes a las universidades públicas a partir de la edad de los setenta años.

11.17 La citada previsión, desde mi punto de vista y acorde con la posición que ya he sostenido en alguna otra oportunidad, deviene en discriminatoria al pretender asumir una postura absolutista en relación con la capacidad docente, como si esta dependiera única y exclusivamente de factores temporales.

$(\ldots)^{\prime \prime}$

Coincidimos con los argumentos esgrimidos por estos magistrados. Con el artículo bajo análisis se pone en tela de juicio la capacidad de un docente universitario únicamente por el hecho de haber cumplido 70 años de edad. Se le asocia con una persona frágil y no apta para ejercer su profesión. Además, no advertimos una causa razonable del legislador para haber incluido esa edad como límite para tal fin, cuando en la anterior Ley Universitaria, Ley $\mathrm{N}^{\circ} 23733$, no se había considerado límite alguno.

En el Informe de Adjuntía №24 - 2017 - DP/AAE se defiende la implementación de políticas laborales más amplias, orientadas a fortalecer la participación de las personas adultas mayores en el ámbito laboral. Asimismo, plantea garantizar el envejecimiento activo e inclusivo en el ámbito laboral para aquellos adultos mayores que decidan seguir trabajando, a pesar de haber cumplido la edad de jubilación obligatoria (Defensoría del Pueblo, 2017). En dicho informe se muestra el rechazo al artículo $84^{\circ}$ de la Ley Universitaria, señalando que no se debería incluir un límite para el ejercicio de la docencia.

Para finalizar este apartado, se considerará un punto de suma importancia, la Ley $N^{\circ} 30697$. Dispositivo legal publicado en el Diario Oficial "El Peruano" el día 16 de diciembre de 2017, y mediante el cual se modifica el cuarto párrafo del artículo 84 de la Ley N³0220 - Ley Universitaria. Entonces, queda redactado de la siguiente manera:

\section{"Artículo 84. Período de evaluación para el nombramiento y cese de profesores ordinarios (...) \\ La edad máxima para el ejercicio de la docencia en la universidad pública es setenta y cinco años, siendo esta la edad límite para el ejercicio de cualquier cargo administrativo y/o de gobierno de la universidad. Pasada esta edad solo podrán ejercer la docencia bajo la condición de docentes extraordinarios. \\ $(\ldots)^{\prime \prime}$.}

El rechazo al cuarto párrafo del artículo $84^{\circ}$ de la Ley Universitaria se traduce en los más de 15 proyectos de ley que se presentaron para su derogación o modificación. Finalmente, este cambio en la legislación surgió como respuesta a la iniciativa legislativa impulsada por el congresista Juan Sheput, mediante Proyecto $N^{\circ} 739$ presentado el 06 de diciembre de 2016. Entre otros motivos, en este documento se expuso que distintos avances científicos y médicos han demostrado que la edad productiva de una persona puede llegar a superar los 70 años.

Asimismo, se señala que la sociedad se verá beneficiada con la enseñanza de profesores mayores de 70 años, que cuenten con condiciones físicas y mentales óptimas. Docentes que trasmitirán a los estudiantes los conocimientos especializados adquiridos en todos sus años de experiencia (Sheput, 2016). En ese sentido, no solo se beneficiarán ellos al continuar trabajando, sino también los alumnos a quienes transmitirá su experiencia.

Si bien cambiar el límite de edad a 75 años ha significado un avance legislativo importante, que aporta a la propuesta de este informe; si lo que se 
pretende es erradicar la discriminación por razón de edad y garantizar el derecho al trabajo del adulto mayor, el criterio para que éste permanezca o se reinserte en el mundo laboral no debería ser su edad. Un requisito idóneo sería la evaluación de su capacidad mental y física, a fin de determinar si es apto para el desempeño de su cargo, en este caso, la docencia universitaria.

\subsection{Propuesta de medidas jurídicas de permanencia y reinserción laboral del adulto mayor}

El Perú no es ajeno al fenómeno poblacional de carácter mundial, conocido como la globalización de la vejez. El mismo impacta en distintos ámbitos de la sociedad, entre ellos, el laboral (Poblete, 2008). En la actualidad se pretende una vejez más activa en todas las dimensiones de la vida del hombre. En ese sentido, la reinserción laboral de los adultos mayores se presenta como una forma de realización personal de este sujeto.

El derecho al trabajo del adulto mayor ha sido abordado en la normativa y en las políticas de nuestro país. Sin embargo, no se le brinda el tratamiento pormenorizado que merece. Ello, en tanto no se ha regulado las medidas jurídicas necesarias para hacer efectiva la atención a la empleabilidad de este grupo etario. Esta situación genera dificultades al momento de hacer realidad las políticas públicas formuladas al respecto.

Por tanto, este estudio propone tres medidas jurídicas específicas que deberán tenerse en cuenta para la permanencia y la reinserción laboral de los adultos mayores. Las mismas que tendrán como fundamento lo que la doctrina, legislación y jurisprudencia han considerado hasta el momento.

\subsubsection{Programa especial de empleo para lograr la reinserción laboral del adulto mayor}

Los programas especiales de empleo se diseñan a fin de impulsar la inserción laboral de distintos grupos con limitaciones en el acceso al mercado de trabajo. Nuestra legislación ha previsto su aplicación a través del D.S. N02-97-TR, que aprueba la Ley de Formación y Promoción Laboral. En esta norma se precisa que será el Ministerio de Trabajo y Promoción del Empleo la cartera encargada de implementar dichos programas de forma periódica.

A modo de ejemplo, encontramos al Programa Nacional para la Generación de Empleo Social Inclusivo denominado "TRABAJA PERÚ", que se implementó en nuestro país en el año 2014; y pretende generar trabajo temporal destinado a la población en edad de trabajar (a partir de 18 años), en situación de pobreza, pobreza extrema, o afectada parcial o íntegramente por desastres naturales o por emergencias.

En relación a este programa, como vemos, no se ha precisado límite de edad, por lo que podríamos incluir en él a las personas mayores de 60 años. No obstante, creemos que ello no sería de utilidad, en tanto, representa una iniciativa de carácter general. Mientras que, a lo largo de este informe, se ha establecido que un programa dirigido a adultos mayores debe considerar medidas específicas que atiendan sus especiales características y promuevan una vejez plena y productiva. A continuación, revisaremos las disposiciones legales que, al respecto, se prevén.

En el artículo $36^{\circ}$ del D.S. N02-97-TR se establece que los programas especiales de empleo atenderán las características de los segmentos de la fuerza laboral a los que se dirigen, determinando medidas y acciones específicas según las necesidades de cada grupo. Aporte que se considera relevante, en tanto cada grupo poblacional posee peculiaridades que se traducen en necesidades distintas. Asimismo, se indica que estos programas tendrán, en todos los casos, duración determinada.

Otra disposición importante es la que encontramos en el artículo $37^{\circ}$ de la misma norma. En la misma se ha determinado, respecto a los grupos laborales beneficiarios, lo siguiente:

"Artículo 37.- Las categorías laborales que podrán beneficiarse principalmente de los programas especiales de empleo serán las siguientes:

a) Mujeres con responsabilidades familiares sin límite de edad;

b) Trabajadores mayores de cuarenticinco (45) años de edad en situación de desempleo abierto, cesados por causa de programas de reconversión productiva o mediante convenios de productividad; $y$,

c) Trabajadores con limitaciones físicas, intelectuales o sensoriales."

Como podemos apreciar, no ha contemplado al adulto mayor como categoría beneficiaria. Si bien podríamos incluirlos en el grupo destinado a personas mayores de 45 años, el cual no establece una edad máxima, se considera que, tal y como se precisa en esta misma 
norma, cada grupo poblacional es singular. Es decir, posee características distintas que merecen atención especializada; por lo que sería ideal que exista una categoría distinta para este grupo etario.

Sin que signifique oposición a la clasificación establecida, el propio dispositivo legal establece una excepción, contemplada en su artículo $38^{\circ}$. En la cual señala que el Ministerio de Trabajo, a través de un Decreto Supremo, podrá habilitar otros programas especiales de fomento del trabajo en atención a criterios objetivos adicionales. Se contemplan, además, distintas medidas a tener en cuenta en la implementación de los programas, tales como la capacitación laboral, la orientación y formación profesional y los incentivos.

Sobre la base de las disposiciones previstas en el D.S. $\mathrm{N}^{\circ} 02-97-T R$, este estudio propone, como una de las alternativas para la reinserción laboral de los adultos mayores, la implementación de un programa especial de empleo dirigido a este grupo poblacional. Programa que deberá habilitarse por medio de un Decreto Supremo del Ministerio de Trabajo y Promoción del Empleo. Además, considerará actividades laborales que puedan ser desempeñadas por las personas de tercera edad.

La propuesta tiene además sustento jurídico de carácter internacional, en el artículo $17^{\circ}$ denominado "Protección de los Ancianos" del Protocolo de San Salvador, ratificado por nuestro país. En él se establece que los Estados parte, deberán ejecutar programas laborales específicos destinados a conceder a los ancianos la posibilidad de realizar una actividad productiva adecuada a sus capacidades, respetando su vocación o deseos.

Para la implementación del programa propuesto, planteamos las siguientes recomendaciones adicionales:

a) La creación de un registro con información de los adultos mayores en el Perú, que considere su situación laboral, pensionaria, de capacitación y de salud. Ello a fin de priorizar la inclusión laboral de aquellos adultos mayores que no cuenten con pensión de jubilación.

Al respecto, el artículo $17^{\circ}$ de la Ley del Adulto Mayor prevé la creación del Registro de organizaciones de personas adultas mayores y de las instituciones que implementan acciones a su favor; sin embargo, no se contempla el registro que sugerimos. b) Creación de grupos intergeneracionales en las organizaciones, para lograr que los adultos mayores no sean excluidos de las empresas, sino que exista un intercambio de conocimientos, entre los trabajadores de la tercera edad y los más jóvenes.

c) Fiscalización de forma periódica, mediante la evaluación y supervisión del trabajador adulto mayor que ha obtenido un trabajo, se brindará un soporte al proceso de su reinserción. Con ello se pretende evitar las dificultades de retorno o permanencia en el empleo de este grupo etario, lo cual beneficiaría tanto en el trabajador como en el empleador.

d) En lo que concierne al ambiente físico de trabajo, entre otras acciones, se deberá evitar el trabajo pesado. Es decir, que incluya varias horas pie o implique esfuerzo intenso.

e) Reducción de las jornadas de trabajo, limitar el trabajo en horario nocturno y promover la flexibilidad laboral.

f) Capacitación constante en nuevas tecnologías.

\subsubsection{Actualización para la reinserción laboral: una alternativa de empleo para el adulto mayor}

La preparación económica para la vejez, la creación de oportunidades de trabajo y la reducción en las tasas de informalidad se logrará si garantizamos el acceso universal a educación de calidad. Por ello, una estrategia para el aumento de trabajo formal es la creación de programas de capacitación que faciliten la transición al mercado laboral (Martínez, 2015). En ese escenario, encontramos el término "Gerontagogía", el cual se refiere a la educación del adulto mayor, como una necesidad y exige a los docentes métodos de atención especial a esta población.

La Ley $N^{\circ} 28518$ - Ley sobre modalidades formativas laborales, define a éstas como tipos especiales de convenios que relacionan el aprendizaje teórico y práctico, a través del desarrollo de tareas programadas de capacitación y formación profesional. En el artículo III de la referida Ley, se prevé que el ámbito de aplicación comprende a todas las empresas sujetas al régimen laboral de la actividad privada, sean del sector público o privado.

Asimismo, en su artículo $2^{\circ}$ presenta la clasificación de las modalidades formativas en nuestro país y encontramos en el numeral 5 denominado "De la actualización para la Reinserción Laboral" en la categoría de pasantía, una alternativa para que los 
adultos mayores se reinserten en el mundo laboral. Sin embargo, la aplicación de este tipo de modalidad formativa es casi nula, lo que quizás se deba a la falta de promoción o de incentivos para su puesta en práctica.

Según el Boletín Anual sobre Modalidades Formativas del periodo de enero a diciembre de 2019, los beneficiarios a nivel nacional fueron un total de 57178 personas. De las cuales 27974 personas, correspondieron a Prácticas Pre Profesionales; 19 726, a Prácticas Profesionales; 7 681, al grupo de Aprendizaje con Predominio en la Empresa; 1 144, a Capacitación Laboral Juvenil; 588, a Pasantía en la Empresa; y finalmente, solo 65 personas fueron beneficiarias de la categoría de Actualización para la Reinserción Laboral y Pasantía de Docentes y Catedráticos (Ministerio de Trabajo y Promoción del Empleo, 2020).

Como es evidente, las empresas presentan mayor interés en efectuar convenios en la categoría de aprendizaje, frente a la posibilidad de poner en práctica el tipo de modalidad formativa en el grupo de actualización. Una manera de dar a conocer esta posibilidad de inserción en el empleo, prevista en la ley, será justamente promoviendo, a través de ella, la incorporación laboral de adultos mayores, grupo poblacional que, como hemos visto, se encuentra en constante crecimiento.

El convenio de actualización para reinserción laboral se prevé en el Capítulo $V$ de la ley en mención. Este se caracteriza por realizar el proceso de actualización para la reinserción en las unidades productivas de las empresas. Así permite a los beneficiarios la recalificación, ejercitando su desempeño en una situación real de trabajo, complementada con el acceso a servicios de formación y de orientación para la inserción en el mercado laboral.

Es pertinente recordar que las modalidades formativas laborales se concretan a través de un convenio suscrito entre la empresa y el beneficiario que, en este caso, sería el adulto mayor. El mismo que tiene una duración no mayor a doce (12) meses, prorrogable por otro período similar. En cuanto a la subvención económica mensual que reciben, en el caso de la Actualización para la Reinserción Laboral, no puede ser menor de dos remuneraciones mínimas. Asimismo, esta no posee carácter remunerativo $\mathrm{y}$, por tanto, no se encuentra afecta al pago de ninguna contribución que genere alguna carga económica a la empresa.
La jornada prevista para este tipo de modalidad no puede ser mayor a ocho (08) horas diarias y cuarenta y ocho (48) horas semanales, salvo excepciones que la norma señala. Ahora bien, según lo dispuesto en el artículo $30^{\circ}$ de la norma, los beneficiarios de la Actualización para la Reinserción Laboral son personas entre 45 y 65 años de edad que se encuentren en situación de desempleo prolongado, mayor a doce (12) meses continuos, habiéndose desempeñado como trabajadores sean empleados y/u obreros del sector público o privado.

La propuesta de incluir a los adultos mayores en la mencionada categoría formativa se hace posible en tanto el inciso 1 del artículo I de la Ley de Modalidades Formativas establece, como uno de los principios que regirán todas sus disposiciones, a la persona como centro fundamental del proceso de formación, teniendo como meta que éstas alcancen su medio social y de trabajo. Consideraciones que además coinciden con lo establecido en la ley y el reglamento del adulto mayor. Siendo así, esta será una medida adecuada para reinsertar al adulto mayor en el trabajo, dado que la capacitación lo ayudará a afrontar con éxito la vida laboral.

Teniendo en cuenta lo propuesto en esta investigación, se deberá considerar el criterio de edad para incluir en el artículo $30^{\circ}$ de la Ley sobre Modalidades Formativas, dos grupos etarios. El primero de ellos, en el rango de 45 a 60 años de edad; y el otro, de 60 a más. De esa forma, la política pública que nuestro país ha adoptado sobre el adulto mayor, estará acorde con la normativa internacional y los avances que, en ese sentido, orientan a los objetivos del desarrollo sostenible a nivel mundial.

\subsubsection{Medidas de carácter económico a favor de las empresas que vinculen laboralmente a los adultos mayores}

Como se ha expuesto a lo largo de este estudio, el crecimiento acelerado de la población adulta mayor repercute en el mercado laboral. El incremento en la longevidad de las personas ha conllevado a que en distintos países del mundo se adopten medidas legislativas para promover la contratación de este sector poblacional. Para lo cual se tiene en cuenta sus características, y las dificultades que enfrentan para insertarse laboralmente.

A fin de lograr la inclusión social de las poblaciones vulnerables, como los adultos mayores, se deberá 
priorizar el principio de igual de oportunidades. A nivel mundial se proponen, por ejemplo, medidas jurídicas de carácter tributario a fin de fomentar que las empresas vinculen laboralmente a este grupo etario. Sin ir muy lejos, en este estudio se han presentado las experiencias de dos países latinoamericanos, estos son México, que incluyó en su Ley del Impuesto sobre la Renta este tipo de estímulo; y, de igual manera, Colombia, con la reciente promulgación de la Ley $\mathrm{N}^{\circ} 2040$.

En esta investigación se han propuesto medidas a favor del adulto mayor y su empleabilidad, como la creación de programas especiales de trabajo y la implementación de pasantías en las empresas. Las cuales deberán prever condiciones adecuadas a las características propias del trabajador adulto mayor. No obstante, sabemos que estas exigencias ocasionarían mayor inversión del empleador, lo que puede generar efectos contrarios a los buscados; como la exclusión laboral de este sector poblacional y el aumento de la informalidad.

Por tanto, se propone otorgar beneficios a las empresas que decidan incorporar en sus planillas a trabajadores de la tercera edad. El incentivo que se propone es de carácter económico y toma en cuenta lo regulado en la Ley №29973 - Ley General de la Persona con Discapacidad y su Reglamento. Estas normas prevén distintos mecanismos a fin de incentivar la contratación laboral de las personas con discapacidad, grupo poblacional con dificultades para el acceso al trabajo.

En el artículo $49^{\circ}$ del texto legal en comentario se ha implementado la llamada cuota laboral. La misma prevé la contratación de una proporción de discapacitados, no inferior al 5\% de la totalidad de trabajadores, en entidades públicas. Mientras que, para empleadores privados, con más de cincuenta trabajadores, una proporción no inferior al $3 \%$. En el inciso $2^{\circ}$ del artículo $47^{\circ}$ de la mencionada ley, se indica que las entidades públicas o privadas, que empleen personas con discapacidad obtendrán una deducción adicional en el pago del impuesto a la renta sobre las remuneraciones de estos trabajadores.

Entonces, para la contratación de personas de la tercera edad será necesario la suscripción de un acuerdo entre el Ministerio de Economía y Finanzas y el Ministerio de Trabajo y Promoción del Empleo. De manera que aquellos empleadores públicos y privados que generen rentas de tercera categoría y que contraten a adultos mayores gozarían de una deducción adicional en el pago del impuesto a la renta, a la que se refiere el inciso $2^{\circ}$ del artículo $47^{\circ}$ de la Ley $N^{\circ} 29973$.

La propuesta formulada reconoce que, si bien este tipo de iniciativas son importantes para garantizar el cumplimiento de los derechos de las personas mayores, las situaciones a las que se enfrenta este sector de la población son mucho más complejas. Motivo por el cual se debe trabajar más con empresas y determinar cuáles son las disposiciones laborales para contratar a adultos mayores. Por ejemplo, conocer los criterios de selección y su justificación (Marquez, 2015). Ello porque si bien muchas empresas confirman la capacidad y el potencial de los adultos mayores, rescatando su experiencia; en otras, prevalece la visión negativa de la vejez.

Para finalizar, se considera que si lo que se pretende es la efectiva reinserción del adulto mayor en el ejercicio laboral, no basta con proponer su contratación mediante programas especiales, sino que se torna necesario el impulso de beneficios tributarios por parte del Estado. Así se logrará que las empresas encuentren una motivación para contratar con adultos mayores que se encuentran debidamente calificados para acceder a un puesto de trabajo.

\section{Conclusiones}

En el Perú el incremento de la proporción de adultos mayores es notoria, pasa de constituir el 5,7\% de nuestra población en 1950, al 12,7\% en el año 2020. Los adultos mayores que están incluidos en la Población Económicamente Activa constituyen el 55,4\%. Las estadísticas sobre empleo muestran que, de cada 10 personas de 60 a más años de edad -definición de adulto mayor adoptada por la OMS y el artículo 2으 de la Ley de la Persona Adulta Mayor-, aproximadamente, 6 participan en el mercado laboral. La población adulta mayor continúa trabajando por las nulas o insuficientes pensiones de jubilación o porque, pese a tener solvencia económica, desean continuar haciendo lo que han hecho durante toda su vida: trabajar.

En nuestro país, además de la Constitución, existen tres normas principales a favor de las personas adultas mayores: la Ley $N^{\circ} 30390$, Ley de las Persona Adulta Mayor, el Decreto Supremo N002-2013-MIMP, que aprobó el Plan Nacional para las personas Adultas Mayores 2013-2017 y el Decreto Supremo N007-2018MIMP, que aprueba el reglamento de la citada ley. Normativa que regula ampliamente el trabajo para este sector de la población y destaca que para la promoción de oportunidades de empleo para personas de la 
tercera edad el Estado en sus tres niveles de gobierno, debe promover, capacitar, gestionar y crear oportunidades de empleo, autoempleo productivo y formal, así como emprendimientos productivos para personas adultas mayores de acuerdo a su experiencia de vida, condición de salud y respeto a su autonomía.

Nuestro país, aunque con diferentes grados de volumen e intensidad, atraviesa un inexorable fenómeno de envejecimiento. Situación que genera desafíos y exigencias de diferente naturaleza, en términos de implementación de políticas públicas en todos los ámbitos. A nivel nacional destacan el Acuerdo Nacional 2016 - 2021, el Plan Nacional de Derechos Humanos 2018-2021 y el Plan Nacional de Personas Adultas Mayores 2013 - 2017. Mientras que, a nivel regional, el Plan de Desarrollo Regional Concertado de Lambayeque 2011 - 2021. Instrumentos en los cuales, en mayor o menor medida, se han previsto lineamientos que tienen como fin la reinserción y permanencia laboral del adulto mayor.

La legislación de nuestro país considera el derecho al trabajo del adulto mayor. En ese sentido existen políticas públicas a nivel nacional, dirigidas al logro de este fin. Sin embargo, la normativa no ha considerado medidas jurídicas específicas para hacer efectivas las políticas públicas dirigidas a la reinserción y permanencia laboral de los adultos mayores, motivo por el cual este estudio propone la adopción de las siguientes medidas jurídicas: i) Programa especial de empleo para lograr la reinserción laboral del adulto mayor; ii) Actualización para la reinserción laboral: una alternativa de empleo para el adulto mayor y iii) Medidas de carácter económico a favor de las empresas que vinculen laboralmente a los adultos mayores.

\section{Bibliografía}

Alarco, Germán (2010). Avances y límites luego del Acuerdo Nacional y el Plan Perú 2021.

http://www2.congreso.gob.pe/sicr/cendocbib/con4 ui bd.nsf/CB1DB69FEC88EC3A05257C7C006577FC/\$FILE/ avancesylimitesluegodelacuerdonacional.pdf.

Arriaga, Paula y otros (2016). Políticas de Estado y Planes de Gobierno 2016 - 2021. Perú: Secretaría

Ejecutiva del Acuerdo Nacional.

http://acuerdonacional.pe/wp-

content/uploads/2016/03/Politicas-de-Estado-y-

Planes-de-Gobierno-2016 2021.pdf.
Blouin, Cécile (2018). La situación de la población adulta mayor en el Perú: Camino a una nueva política. Perú: Pontificia Universidad Católica del Perú. https://cdn01.pucp.education/idehpucp/wpcontent/uploads/2018/11/23160106/publicacionvirtual-pam.pdf.

Cardona Arango, Doris y Peláez, Enrique (2012).

"Envejecimiento poblacional en el siglo XXI: oportunidades, retos y preocupaciones". Revista Científica Salud Uninorte, 28 (2), 335 - 348. http://www.scielo.org.co/pdf/sun/v28n2/v28n2a15.pd f.

Castillo Herrera, José (2011). "El envejecimiento humano activo y saludable, un reto para el anciano, la familia, la sociedad". Revista Cubana de Investigaciones Biomédicas, 30 (3), 354 - 359. http://scielo.sld.cu/scielo.php?pid=S0864$\underline{03002011000300006 \& \text { script=sci arttext\&tlng=en. }}$.

Centro Nacional de Planeamiento Estratégico (2011). Plan Bicentenario. El Perú hacia el 2021. Perú: Punto \&Grafía S.A.C.

Comisión de Educación, Juventud y Deporte (2017). Periodo Anual de Sesiones 2017 - 2018. Perú:

Congreso de la República.

http://www.leyes.congreso.gob.pe/Documentos/2016 2021/Dictamenes/Proyectos de Ley/00503DC10MA $\underline{\text { Y20171030.pdf- }}$

Comisión Económica para América Latina y El Caribe (2019). Envejecimiento y derechos humanos: la Convención Interamericana sobre la Protección de los Derechos Humanos de las Personas Mayores. https://bit.ly/34S4CQW .

Defensoría del Pueblo (2019). Envejecer en Perú: Hacia el fortalecimiento de las políticas para personas adultas mayores. Informe de Adjuntía Nº06-2019DP/AAE. https://www.defensoria.gob.pe/wpcontent/uploads/2019/08/DEFENSOR\%C3\%8DA-DELPUEBLO-INFORME-ENVEJECER-EN-EL-PER\%C3\%9A.pdf.

Defensoría del Pueblo (2017). Sobre el límite de edad como causal de cese del ejercicio de la docencia en las universidades públicas. Informe de Adjuntía № 24 2017 - DP/AAE. https://www. defensoria.gob.pe/wpcontent/uploads/2018/05/Informe-de-Adjuntia-0242017-DP-AAE.pdf. 
Federación Iberoamericana de Asociaciones de Personas Adultas Mayores (2019). América Latina envejece a pasos de gigante.

https://fiapam.org/america-latina-envejece-a-pasosde-

gigante/\#: :text=Si\%20en\%20este\%20momento\%2C\% 20el,ser\%C3\%A1\%20mayor\%20de\%2060\%20a\%C3\%B1 os.

Gobierno Regional de Lambayeque (2017). Plan de Desarrollo Regional Concertado Lambayeque al 2021. http://ot.regionlambayeque.gob.pe/upload/pdf/archiv o 599da9e43e04b.pdf.

Huenchuan, Sandra y Rodríguez-Piñero, Luis (2010). Envejecimiento y Derechos Humanos: Situación y Perspectivas de Protección. Chile: CEPAL http://repositorio.cepal.org/bitstream/handle/11362/3 803/lcw353 es.pdf.

Huenchuan, Sandra (2011). Hacia un cambio de paradigma sobre el envejecimiento y la vejez. En Los derechos de las personas mayores. Chile: CEPAL. http://fiapam.org/wpcontent/uploads/2012/10/Modulo 1.pdf.

Instituto Nacional de Estadística e Informática (2020). Estado de la población peruana 2020. https://www.inei.gob.pe/media/MenuRecursivo/public aciones digitales/Est/Lib1743/Libro.pdf.

Instituto Nacional de Estadística e Informática (2020). Situación de la Población Adulta Mayor. Enero, febrero, marzo 2020. Informe técnico No 02 - junio 2020.

https://www.inei.gob.pe/media/MenuRecursivo/boleti nes/informe-tecnico-poblacion-adulta-mayor.pdf.

Martinez-Restrepo, Susana y otros (2015). El mercado laboral y las personas mayores. Colombia: Editorial Fundación Saldarriaga Concha.

https://saldarriagaconcha.org/mce/pdf/MCE-C3.pdf.

Marquez, Mario Alfonso (2015). Inserción laboral de adultos mayores en Chile: Una aproximación cualitativa. (Tesis de pregrado) Universidad de Chile. Chile http://repositorio.uchile.cl/bitstream/handle/2250/16 7745/Inserci\%c3\%b3n\%20laboral\%20de\%20adultos\%2 Omayores\%20en\%20Chile.pdf?sequence=1\&isAllowed $=\mathrm{y}$.
Ministerio de la mujer y poblaciones vulnerables (2013). Cuadernos sobre poblaciones vulnerables № 05. PLANPAM 2013 - 2017.

https://www.mimp.gob.pe/files/mimp/especializados/ boletines dvmpv/cuaderno 5 dvmpv.pdf.

Ministerio de Trabajo y Promoción del Empleo (2020). Boletín Anual sobre Modalidades Formativas Laborales declarados en el T-Registro de la Planilla Electrónica. Enero - diciembre 2019.

https://cdn.www.gob.pe/uploads/document/file/8659 OO/BOLETIN ANUAL 2019 12.06.20.pdf.

Ministerio de Justicia (2019). Plan Nacional de Derechos Humanos 2018 - 2021.

http://spij.minjus.gob.pe/content/banner secundario/i mg/muestra/PLAN-ANUAL.pdf.

Murrugarra, Edmundo (2011). Empleabilidad y productividad entre trabajadores mayores: Un marco de política y evidencia en Latinoamérica.

https://app.vlex.com/\#WW/search/*/EMPLEABILIDAD + Y+PRODUCTIVIDAD+ENTRE+TRABAJADORES+MAYORE S\%3A/WW/vid/413894378.

Neves Mujica, Javier (2010). La edad como causal de extinción o de restricción de la relación laboral en nuestro ordenamiento. En Derecho del Trabajo. Cuestiones controversiales. Perú: Ara editores.

Organización de Los Estados Americanos (2015). Convención Interamericana sobre la Protección de los Derechos Humanos de las Personas Mayores.

http://www.oas.org/es/sla/ddi/docs/tratados multilat erales interamericanos $\mathrm{A}$ -

70 derechos humanos personas mayores.pdf.

Organización Mundial De La Salud (2015). Informe Mundial sobre el envejecimiento y la salud.

https://apps.who.int/iris/bitstream/handle/10665/186 466/9789240694873 spa.pdf?sequence=1.

Orosa, Teresa (2001). Determinantes del Desarrollo en la Psicología de la Vejez. Chile: IV Congreso Chileno de Antropología.

https://www.aacademica.org/iv.congreso.chileno.de.a ntropologia/62.pdf.

Palma, Andrea y otros (2019). Las personas mayores como sujetos de derecho: El aporte de la Convención Interamericana sobre la protección de los derechos de las personas mayores. Montevideo: Ministerio de Desarrollo Social. Instituto Nacional de Personas 
Mayores.

https://www.cepal.org/sites/default/files/events/files/ documento inmayores final $0 . p d f$.

Paz, Jorge A. (2010). Envejecimiento y Empleo en América Latina y el Caribe. Suiza: Organización Internacional del Trabajo.

http://www.ilo.org/wcmsp5/groups/public/@ed emp/ @emp policy/documents/publication/wcms 140847.p df.

Pérez Hernández, Ana María (2014). La percepción social en la vejez. España: Universidad de la Laguna https://riull.ull.es/xmlui/bitstream/handle/915/585/La \%20percepcion\%20social\%20de\%20la\%20vejez.pdf?se quence $=1$.
Poblete, Ricardo y Retamal, César (2008). Inserción laboral en la vejez. (Tesis de pregrado) Universidad de Chile, Chile.

http://repositorio.uchile.cl/handle/2250/106866.

Ramos, Miguel y otros (2009). Las personas adultas mayores y su contribución a la lucha contra la pobreza. Perú: Fondo de Población de las Naciones Unidas. https://www.mimp.gob.pe/webs/mimp/sispod/pdf/48. pdf.

Saad, Paulo (2017) Envejecimiento provocará caída de la población de América Latina y el Caribe hacia 2060. https://www.cepal.org/es/comunicados/cepalenvejecimiento-provocara-caida-la-poblacion-americalatina-caribe-2060. 